\title{
Predictive modelling of temperature and water activity (solutes) on the in vitro radial growth of Botrytis cinerea Pers
}

\author{
Rachid Lahlali $^{\text {a }}$, M. Najib Serrhini ${ }^{\text {b }}$, Damien Friel ${ }^{\text {a }}$, M. Haïssam Jijakli ${ }^{\text {a,* }}$ \\ ${ }^{a}$ Unité de Phytopathologie, Faculté Universitaire des Sciences Agronomiques de Gembloux, Passage des Déportés 2, 5030 Gembloux, Belgium \\ b Département de Phytopathologie, Ecole Nationale d'Agriculture de Meknès, B. P S/40, 50001 Meknès, Morocco
}

Received 10 March 2006; received in revised form 16 October 2006; accepted 3 November 2006

\begin{abstract}
The objective of this work was to develop validated models predicting the 'in vitro' effect of $a_{\mathrm{w}}$ and temperature on the radial growth of Botrytis cinerea. The growth rate $\left(g, \mathrm{~mm} \mathrm{~d}^{-1}\right)$ of $B$. cinerea was calculated at three incubation temperatures $\left(25^{\circ} \mathrm{C}, 15^{\circ} \mathrm{C}, 5{ }^{\circ} \mathrm{C}\right)$ and six water activities (ranging from 0.995 to 0.890 ). The water activity was adjusted with glucose, $\mathrm{NaCl}$, glycerol, or sorbitol. Statistical analysis showed a significant effect of temperature, solute, $a_{\mathrm{w}}$, and their two- and three-way interactions on the growth rate. No growth was observed at $a_{\mathrm{w}}=0.93$ in the presence of $\mathrm{NaCl}$ or at 0.89 in the presence of a non-ionic solute. The maximum colony growth rate decreased when the incubation temperature and water activity was lowered. Secondary models, relating the colony growth rate with $a_{\mathrm{w}}$ or $a_{\mathrm{w}}$ and temperature were developed. Optimum $a_{\mathrm{w}}$ values for growth ranged from 0.981 to 0.987 in glycerol-, sorbitol-, or glucose-modified medium and were close to 1 in NaClmodified medium. A quadratic polynomial equation was used to describe the combined effects of temperature and $a_{\mathrm{w}}$ on $g\left(\mathrm{~mm} \mathrm{~d}^{-1}\right.$ ) in the presence of each solute. The highest and lowest radial growth rates were observed in models based on glucose and $\mathrm{NaCl}$ respectively, whatever the incubation temperature. All models prove to be good predictors of the growth rates of $B$. cinerea within the limits of experiments. The quadratic polynomial equation has bias factors of $0.957,1.036,0.950$, and 0.860 and accuracy factors of $1.089,1.070,1.120$ and 1.260 in media supplemented with glucose, $\mathrm{NaCl}$, glycerol and sorbitol respectively. The results from modelling confirm the general finding that $a_{\mathrm{w}}$ has a greater influence on fungal growth than temperature.

(C) 2006 Elsevier B.V. All rights reserved.
\end{abstract}

Keywords: Solute; Temperature; Growth rate; Water activity; $B$. cinerea; Predictive modelling

\section{Introduction}

Botrytis cinerea Persoon: Fries (known as "grey mould") causes serious pre- and post-harvest diseases in at least 235 plant species (Jarvis, 1977; Agrios, 1988), including a range of agronomically important crops such as grapes, apples, pears, tomatoes, strawberries, cucumbers, bulb flowers, and ornamental plants. B. cinerea control strategy mainly relies on chemical treatments. Nevertheless alternative strategies, such as integrated pest management, including a combination of several control methods (farming practices, chemical and biological control) are under development (Köhl et al., 1995; Elad, 1996; Jijakli and Lepoivre, 1998). Indeed, effective integrated pest management control of this pathogenic fungus relies on good knowledge of

\footnotetext{
* Corresponding author. Tel.: +32 81622431; fax: +32 81610126 .

E-mail address: jijakli.h@fsagx.ac.be (M.H. Jijakli).
}

infection cycle in order to reduce the number of unnecessary spray applications when $B$. cinerea is not threatening and to improve the timing of spray applications when conditions are favourable for disease development (Ellison et al., 1998a). An expert system for management of $B$. cinerea was developed and validated in Australian vineyards (Ellison et al., 1998a,b). Information given by this system led to a reduction of the number of chemical spray as compared to classical chemical approach.

Because the optimal temperature for mycelial growth, sporulation, and conidial germination ranges from 18 to $23{ }^{\circ} \mathrm{C}$, $B$. cinerea is essentially present in temperate and subtropical regions (Bondoux, 1992). Nevertheless, the pathogen is also active at lower temperatures since conidium germination and mycelial growth can occur at temperatures as low as $0{ }^{\circ} \mathrm{C}$ (Jarvis, 1980; Agrios, 1988; Gindro and Pezet, 2001). Under favourable conditions, a complete infection cycle can occur in 3 to 4 days, depending on the type of host tissue attacked. 
After the contact between conidium and the host tissue, a number of factors influence its germination. Free surface water or a high relative humidity $(>93 \% \mathrm{RH})$ is required for germination and penetration of the host epidermis (Williamson et al., 1995). Moisture helps the pathogen to take up nutrients present on the host epidermis or on pollen grains (Blakeman, 1980). In contrast, when dry conidia are inoculated onto a plant surface and subsequently incubated in the absence of free surface water, the germ tube that would normally affect penetration remains shorter than the length of a conidium (Salinas and Verhoeff, 1995; Williamson et al., 1995; Cole et al., 1996).

There have been few reports on the effects of environmental factors like $a_{\mathrm{w}}$ and temperature and the influence of solutes on B. cinerea growth under 'in vitro' conditions (Dantigny et al., 2005a). Beside an extensive study focusing on the effect of wind speed, relative humidity and temperature on aerial mycelium produced by B. cinerea (Thomas et al., 1988). The influence of the environment on mycelial infection has been a neglected field of study, although it is known that the process can occur in the absence of free water (Jarvis, 1977).

Mathematical modelling is an efficient tool for assessing how individual or combined environmental factors affect microorganisms that degrade processed foods. Various models have been developed in predictive microbiology for fitting growth curves and estimating biological parameters of food-borne pathogens (McMeekin et al., 1993, 2002). Nevertheless, most of the models derive from models based on bacterial data due to the inherent difficulties in assessment of fungal growth rates and gathering of sufficient suitable and reproducible data (Gibson and Hocking, 1997; Dantigny et al., 2005a). Various workers have developed probability, mechanistic/semi-mechanistic, empirical and thermal death models for a variety of toxigenic and spoilage fungi (Pitt, 1993; Skirdal and Eklund, 1993; Gibson et al., 1994; Marín et al., 1996; Cuppers et al., 1997; El-Halouat and Debevere, 1997; Valík and Piecková, 2001; Sautour et al., 2002). The major objective of the present work was to construct and evaluate models describing the individual and combined effects of water activity and temperature on the radial growth rate of $B$. cinerea for each tested solute.

\section{Materials and methods}

\subsection{Fungi}

B. cinerea strain $\mathrm{V}$ was isolated from rotting strawberry (Plant Pathology Unit, FUSAGx, Belgium). For long-term storage, the strain was placed at $-70{ }^{\circ} \mathrm{C}$ in tubes containing $25 \%$ glycerol. During experiments the initial conidial inoculum was taken from Petri-dish cultures on Potato Dextrose Agar (PDA, Merck, Darmstadt, Germany) medium, preserved at $4{ }^{\circ} \mathrm{C}$ for no more than 6 months.

\subsection{Media}

PDA was used as the basal medium $\left(a_{\mathrm{w}}=0.995\right)$. The $a_{\mathrm{w}}$ of the medium was modified by replacing some of the water with an equal weight of glucose $(200 \mathrm{~g} / \mathrm{l} ; 313.33 \mathrm{~g} / \mathrm{l} ; 583.33 \mathrm{~g} / \mathrm{l}$; $803.33 \mathrm{~g} / 1$ and $933.33 \mathrm{~g} / \mathrm{l}), \mathrm{NaCl}(20 \mathrm{~g} / 1 ; 47.56 \mathrm{~g} / \mathrm{l} ; 105 \mathrm{~g} / \mathrm{l}$; $136.66 \mathrm{~g} / \mathrm{l}$ and $170 \mathrm{~g} / \mathrm{l})$, glycerol $(40 \mathrm{ml} / \mathrm{l} ; 181.66 \mathrm{ml} / \mathrm{l}$; $265 \mathrm{ml} / \mathrm{l} ; 346.66 \mathrm{ml} / \mathrm{l}$ and $406.66 \mathrm{ml} / \mathrm{l})$ or sorbitol $(176.66 \mathrm{~g} / \mathrm{l}$; $243.33 \mathrm{~g} / 1 ; 561.66 \mathrm{~g} / 1 ; 660 \mathrm{~g} / \mathrm{l}$ and $800 \mathrm{~g} / \mathrm{l})$ to obtain $a_{\mathrm{w}}$ levels of $0.980,0.960,0.930,0.910$, and 0.890 at 25,15 , and $5{ }^{\circ} \mathrm{C}$ (Lahlali et al., 2005). An AquaLab CX2T (Decagon Devices, 950 NE Nelson Court Pullman, Washington 99163, USA) was used to determine water activities in the adjusted media with an accuracy of 0.003 . The final media were autoclaved at $120{ }^{\circ} \mathrm{C}$ for $20 \mathrm{~min}$.

\subsection{Inoculation and incubation of $B$. cinerea}

B. cinerea strain was grown on PDA $(\mathrm{pH} 5.6)$ at $25{ }^{\circ} \mathrm{C}$. A conidial suspension adjusted to $1 \times 10^{6}$ spores $/ \mathrm{ml}$ with a Bürker cell was prepared from a $10 \pm 1$-day-old colony culture in sterile distilled water containing $0.05 \%$ Tween 20 . Ten-microlitre aliquots of this suspension were inoculated at the centre of Petri dishes containing a test medium. After inoculation, the Petri plates were sealed in polyethylene bags to prevent water loss and incubated at 5,15 , or $25^{\circ} \mathrm{C}$ for a maximum of 25 days. The preservation of water content in the media were checked by measuring the $a_{\mathrm{w}}$ of inoculated Petri dishes after 25 days at each temperature and no change in the $a_{\mathrm{w}}$ of any tested medium was detected. Each experiment was carried out in triplicate for each solute $-a_{\mathrm{w}}-$ temperature combination.

\subsection{Experimental design}

A fully factorial design run in triplicate was used to generate the growth rate of $B$. cinerea in media modified with glucose, $\mathrm{NaCl}$, glycerol, and sorbitol at three temperatures and six $a_{\mathrm{w}}$ levels.

\subsection{Growth measurement}

The average diameter of each growing mycelial colony was measured daily in two perpendicular directions (Marín et al., 1996; Lahlali et al., 2005) without opening the Petri dishes.

Growth rates $\left(g, \mathrm{~mm} \mathrm{~d}^{-1}\right)$ were calculated for each $a_{\mathrm{w}}-$ solute-temperature combination by linear regression from the linear phase of the growth curve. Simultaneously, the time required ( $t_{\mathrm{v}}$, days) to form a visible colony was evaluated for each solute and each $a_{\mathrm{w}}$ and each temperature (Patriarca et al., 2001).

\subsection{Mathematical and statistical methods}

\subsubsection{Influence of $a_{w}$ temperature, and solute}

The influence of $a_{\mathrm{w}}$, solute, temperature, and their interactions on the radial growth rate was analysed by applying the General Linear Model (GLM) procedure of the Statistical Analysis System (SAS Institute, Cary, NC). Statistical significance was judged at the $P<0.05$ level. When analysis revealed statistically significant differences, Duncan's multiple-range mean separation test was performed. 


\subsubsection{Secondary modelling}

2.6.2.1. Effect of $a_{w}$ A mathematical model proposed by Gibson et al. (1994) was applied to the radial growth rates. This model involves a transformation to the natural logarithm to stabilize the variance of the radial growth rate values. Furthermore, a new transformation of $a_{\mathrm{w}}$ to $b_{\mathrm{w}}$ was made to fit the data to a curve with a simpler shape. The transformation of $a_{\mathrm{w}}$ to $b_{\mathrm{w}}$ was done according to the following formula:

$b_{\mathrm{w}}=\sqrt{\left(1-a_{\mathrm{w}}\right)}$.

The use of lng-versus- $b_{\mathrm{w}}$ curves was more appropriate for parabolic adaptation. The following model (Eq. (2)) was fitted separately for each solute at three temperatures $(25,15$, and $\left.5{ }^{\circ} \mathrm{C}\right)$ :

$\ln g=C_{0}+C_{1} b_{\mathrm{w}}+C_{2} b_{\mathrm{w}}^{2}$

where the coefficients $C_{0}, C_{1}$, and $C_{2}$ were calculated by quadratic regression. The optimum $a_{\mathrm{w}}$ values and the radial colony growth rates at optimum $a_{\mathrm{w}}$ were calculated in each solute model and for each incubation temperature. This was done as follows:

$a_{\mathrm{w}}(\mathrm{opt})=1-\left(\frac{C_{1}}{2 C_{2}}\right)^{2}$

$g($ opt $)=\exp \left(C_{0}-\frac{C_{1}}{4 C_{2}}\right)^{2}$.

The time required $\left(t_{\mathrm{v}}\right)$ for a colony to become visible was also calculated by applying the same modelling approach. The $t_{\mathrm{v}}$ model is:

$\ln t_{\mathrm{v}}=D_{0}+D_{1} b_{\mathrm{w}}+D_{2} b_{\mathrm{w}}^{2}$

where coefficients $D_{0}, D_{1}$, and $D_{2}$ are also estimated by quadratic regression.

2.6.2.2. Combined influence of $a_{w}$ and temperature. A second-order polynomial model (Eq. (6)) was fitted to the radial growth rate data for each solute:

$g=C_{0}+C_{1} b_{\mathrm{w}}+C_{2} b_{\mathrm{w}}^{2}+C_{3} T+C_{4} T^{2}+C_{5} b_{\mathrm{w}} T$

with six coefficients $\left(C_{0}\right.$, intercept; $C_{1}, C_{3}$, linear coefficients; $C_{5}$, interaction coefficient; $C_{2}, C_{4}$, squared coefficients) by means of the statistical software package 'DESIGN-EXPERT ${ }^{\circledR}$ version 6.0., (StatEase, Inc., Minneapolis, USA).

2.6.2.3. Mathematical and statistical validation. To evaluate the performance of the predictive models, i.e. their ability to describe the observed experimental data adequately, we calculated the following mathematical and statistical indices: root mean square error (RMSE), $F$-value, regression coefficient $\left(r^{2}\right)$, bias factor, and accuracy factor (Ross, 1996; te Giffel and
Zwietering, 1999; Dantigny et al., 2005b; Samapundo et al., 2005). $F$-values were calculated and compared with tabulated $F$-values. The RMSE and the bias and accuracy factors were calculated as follows:

RMSE $=\sqrt{\frac{\mathrm{RSS}}{d f}}=\sqrt{\frac{\sum\left(\mu_{\text {observed }}-\mu_{\text {predicted }}\right)^{2}}{d f}}$

Bias factor $=10^{\left[\sum \log \left(\mu_{\text {observed }} / \mu_{\text {predicted }}\right) / n\right]}$

Accuracy factor $=10\left[\sum\left|\log \left(\mu_{\text {observed }} / \mu_{\text {predicted }}\right)\right| / n\right]$.

\section{Results and discussion}

\subsection{Influence of $a_{w}$ temperature, and solute}

The effect of $a_{\mathrm{w}}$, temperature, and solute and their two- and three-way interactions was studied on the radial growth rate of B. cinerea. The results in Table 1 revealed significant effect of each single factor and interaction. These results are in agreement with those reported by Lahlali et al. (2005) for the radial growth rate of $P$. expansum on similarly modified Potato Dextrose Agar medium. Teixidõ et al. (1998) have observed similar effects on the growth rate of Candida sake in nutrient yeast dextrose broth. In our experiment, $B$. cinerea was unable to grow at $a_{\mathrm{w}} \leq 0.89$ in glucose-, sorbitol-, or glycerol-modified medium. When $\mathrm{NaCl}$ was used to adjust the $a_{\mathrm{w}}$, no growth was observed at $a_{\mathrm{w}}=0.93$.

Duncan's multiple-range mean separation test was performed according to each factor (Fig. 1). The results show three statistically homogenous groups, one for each temperature (Fig. 1a). For the $a_{\mathrm{w}}$ factor, similar test distinguished six homogenous groups, one for each $a_{\mathrm{w}}$ value (Fig. 1c). Lastly, the test revealed four homogenous groups for the influence of solute, one for each solute treatment (Fig. 1b). The growth rate was found to decrease with decreasing $a_{\mathrm{w}}$ and temperature and was highest on unmodified medium, followed by the modified media in the order: glucose-, sorbitol-, glycerol-, and $\mathrm{NaCl}-$ modified medium (Fig. 1b).

A previous study carried out on the grape berry surface showed inhibition of B. cinerea growth in an 'in vitro' experiment conducted at $a_{\mathrm{w}}<0.93\left(\mathrm{KCl}, \mathrm{CaCl}_{2}\right)$, but when the

Table 1

Variance analysis of the effects of water activity $\left(a_{\mathrm{w}}\right)$, temperature $(T)$, and solute (Sol) and their two- and three-way interactions on the radial growth rate of $B$. cinerea in unmodified and modified PDA medium

\begin{tabular}{lrccl}
\hline Source & $d f$ & Mean square & $F$-value & $\operatorname{Pr}>F$ \\
\hline$T$ & 2 & 61.7569954 & 9298.05 & $0.0001^{*}$ \\
$a_{\mathrm{w}}$ & 4 & 134.9000508 & 20310.4 & $0.0001^{*}$ \\
Sol & 3 & 13.2964639 & 2001.90 & $0.0001^{*}$ \\
$T \times a_{\mathrm{w}}$ & 8 & 7.9291381 & 1193.80 & $0.0001^{*}$ \\
$T \times$ Sol & 6 & 0.939674 & 141.44 & $0.0001^{*}$ \\
Sol $\times a_{\mathrm{w}}$ & 12 & 2.0478495 & 308.32 & $0.0001^{*}$ \\
$T \times a_{\mathrm{w}} \times$ Sol & 24 & 0.2360443 & 35.54 & $0.0001^{*}$ \\
\hline
\end{tabular}

*Highly significant $P<0.0001$. 
a)

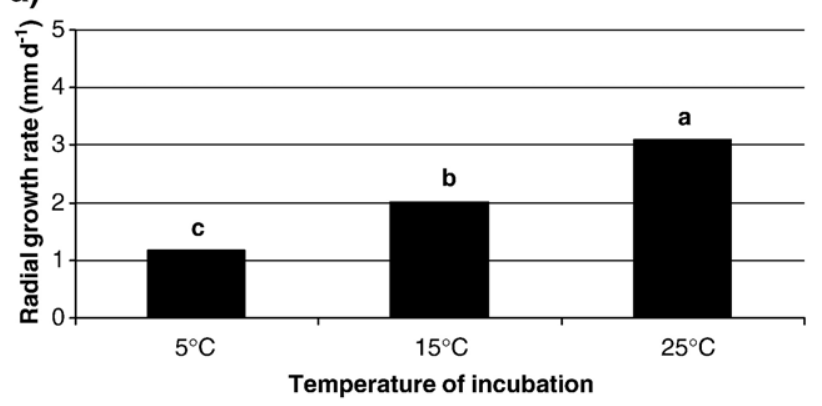

b)

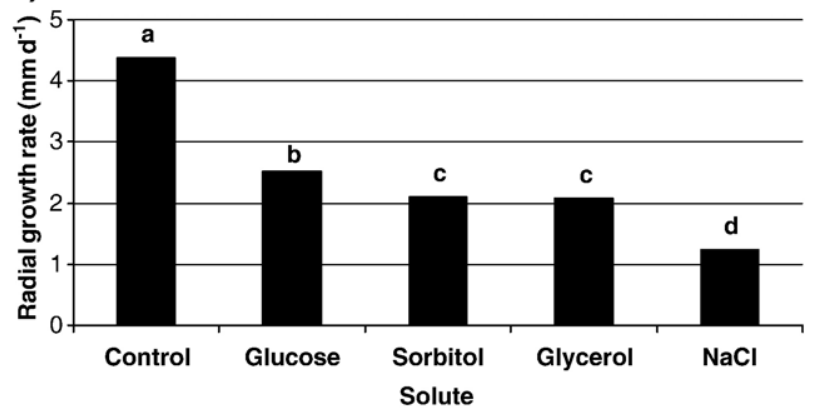

c)

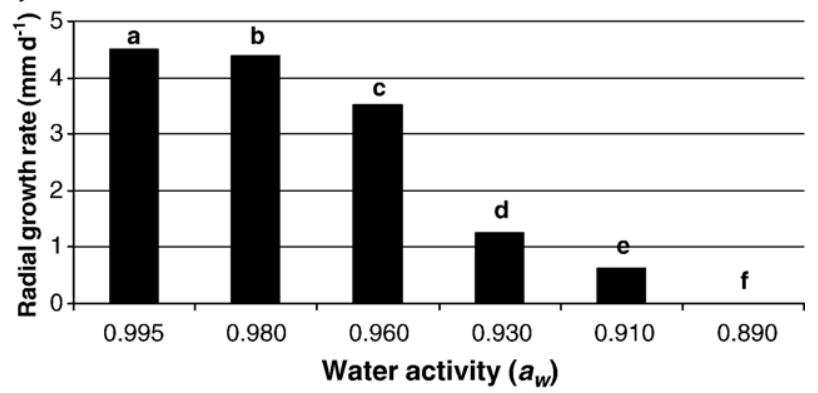

Fig. 1. Mean separation of $B$. cinerea growth rate per incubation temperature (a), solute (b) and water activity level (c), performed by Duncan's multiple-range test. Treatments having the same letters are not significantly different $(P<0.05)$.

medium was supplemented with increasing amounts of sucrose, growth was observed at $a_{\mathrm{w}}<0.93$ (Rousseau and Deneche, 2001). The choice of the solute used to modify the $a_{\mathrm{w}}$ of the PDA medium has a significant impact on the growth rate of $P$. expansum (Lahlali et al., 2005). Abadias et al. (2000) report similar results for the antagonistic yeast $C$. sake. Beuchat and Pitt (1990) also studied the influence of glucose, sorbitol, and $\mathrm{NaCl}$ on fungal growth. They looked at solute effects on colony formation by sublethally heat-stressed Wallemia sebi in a basal enumeration medium at water activities ranging from 0.82 to 0.97 . They report that over this $a_{\mathrm{w}}$ range, glucose and sorbitol had similar effects on the recovery of cells. $\mathrm{NaCl}$, in contrast, had an inhibitory effect over an $a_{\mathrm{w}}$ range of 0.82 to 0.92 . Colony diameters were generally largest on media containing sorbitol and glucose and smallest on media supplemented with $\mathrm{NaCl}$. Our work shows likewise that the non-ionic solutes glycerol, sorbitol, and glucose have a lesser effect on the growth rate of $B$. cinerea than the ionic solute $\mathrm{NaCl}$. Lahlali et al. (2006) proposed that diffusion occurring in both directions across the cell membrane might be the major explanation for the lesser growth observed with $\mathrm{NaCl}$, as $\mathrm{Na}^{+}$and $\mathrm{Cl}^{-}$ions should diffuse more readily than non-ionic solutes from a higherconcentration area to a lower-concentration area, i.e. from PDA medium into the pathogen cells, causing a greater loss of water. Jennings (1983) underlined a weaker growth of fungi in media containing increasing sodium concentration and associated this reduction with a decrease of internal potassium concentration.

\subsection{Effect of $a_{w}$}

Modelling of $B$. cinerea growth was carried out on the basis of the growth data obtained on PDA medium at $\mathrm{pH} 5.6$ under 6 water activities ranging from 0.995 to 0.890 , reached by adding increasing amounts of either a non-ionic solute (glycerol, sorbitol, or glucose) or the ionic solute $\mathrm{NaCl}$. The growth curves, based on colony diameter, were typical of fungal growth, with a germination period followed by an acceleration phase, a linear phase, and finally a slowing towards an upper asymptote (data not shown). Valík and Piecková (2001) obtained similar results with the fungi Byssochlamys fulva, Neosartorya fischeri, and Talaromyces avellaneus at $25^{\circ} \mathrm{C}$, at water activities ranging from 0.85 to 0.995 . Our model (Eq. (2)) was applied to the radial colony growth rates recorded at $a_{\mathrm{w}}$ values ranging from 0.91 to 0.995 for non-ionic solutes and from 0.96 to 0.995 for $\mathrm{NaCl}$. In an empirical modelling approach the effect of $a_{\mathrm{w}}$ on the growth area of $B$. cinerea and the radial growth rate $(g)$, expressed as the increase in colony radius per day, were estimated for each combination of $a_{\mathrm{w}}$ and solute at the three studied temperatures. For each humectant these values were fitted as a function of the $b_{\mathrm{w}}$ parameter by quadratic linear regression. The use of lng led to homogenisation of the variance for parabolic adjustment. Coefficients $C_{0}$, $C_{1}$, and $C_{2}$ used to calculate optimum $a_{\mathrm{w}}$ values for $B$. cinerea growth under various stress conditions are listed in Table 2. The colony growth rates predicted by the secondary models pertaining to the different solutes are shown in Fig. 2.

The results obtained by applying secondary model (Eq. (2)) are in agreement with the experimental observation that temperature has little influence on the $a_{\mathrm{w}}$ optimum for growth. At any temperature and whatever the solute, the $B$. cinerea growth rate appears to increase with the $a_{\mathrm{w}}$. Patriarca et al. (2001) reported similar findings for $W$. sebi at 25 and $30^{\circ} \mathrm{C}$, and Samapundo et al. (2005), Cahagnier et al. (1995), and Marín et al. $(1995,1999 a, b)$ made similar observations on $F$. verticilloides and $F$. proliferatum.

At $25{ }^{\circ} \mathrm{C}$, the optimum $a_{\mathrm{w}}$ for growth was 0.987 in the glucose model, 0.990 in the $\mathrm{NaCl}$ model, and 0.985 in the glycerol and sorbitol models. The corresponding radial growth rates were $7.18,6.75,7.36$, and $7.60 \mathrm{~mm} \mathrm{~d}^{-1}$ respectively. At $15{ }^{\circ} \mathrm{C}$, the growth rates were lower, the highest being $5.34 \mathrm{~mm}$ $\mathrm{d}^{-1}$ (sorbitol, $a_{\mathrm{w}}=0.984$ ) and the lowest being $4.27 \mathrm{~mm} \mathrm{~d}^{-1}$ $\left(\mathrm{NaCl}, a_{\mathrm{w}}=0.994\right)$.

The optimum $a_{\mathrm{w}}$ for growth remained unchanged at $5{ }^{\circ} \mathrm{C}$ in all models except the $\mathrm{NaCl}$ model, where it dropped to 0.989 . The growth rates were drastically reduced, the highest rate being observed in the sorbitol model $\left(3.16 \mathrm{~mm} \mathrm{~d}^{-1}, a_{\mathrm{w}}=0.983\right)$. 
Table 2

Coefficients and some predictions of the radial growth rate (Eq. (2)) and $t_{\mathrm{v}}$ models (Eq. (5)) for $B$. cinerea in modified PDA media with different solutes at different temperatures

\begin{tabular}{|c|c|c|c|c|c|c|c|c|c|c|}
\hline & \multicolumn{5}{|c|}{ Growth rate model } & \multicolumn{5}{|c|}{$t_{\mathrm{v}}$ model } \\
\hline & \multicolumn{3}{|c|}{ Coefficients } & \multicolumn{2}{|c|}{ Characteristics } & \multicolumn{3}{|c|}{ Coefficients } & \multicolumn{2}{|c|}{ Characteristics } \\
\hline & $C_{0}$ & $C_{1}$ & $C_{2}$ & $a_{\mathrm{w}}(\mathrm{opt})_{1}{ }^{\mathrm{a}}$ & $g(\mathrm{opt})^{\mathrm{b}}$ & $D_{0}$ & $D_{1}$ & $D_{2}$ & $a_{\mathrm{w}}(\mathrm{opt})_{2}^{\mathrm{c}}$ & $t_{\mathrm{v}}(\mathrm{opt})^{\mathrm{d}}$ \\
\hline \multicolumn{11}{|l|}{$25^{\circ} \mathrm{C}$} \\
\hline Glu & 1.290 & 10.848 & -42.715 & 0.987 & 7.18 & 2.457 & -17.218 & 56.080 & 0.976 & 3.12 \\
\hline $\mathrm{Na}$ & 1.260 & 13.333 & -68.315 & 0.990 & 6.75 & 1.635 & -7.580 & 45.514 & 0.993 & 3.74 \\
\hline Gly & 1.223 & 12.931 & -53.975 & 0.985 & 7.36 & 2.425 & -16.843 & 55.479 & 0.976 & 3.14 \\
\hline $\begin{array}{l}\text { Sorb } \\
15^{\circ} \mathrm{C}\end{array}$ & 1.045 & 15.928 & -64.508 & 0.985 & 7.60 & 2.214 & -14.135 & 50.032 & 0.980 & 3.37 \\
\hline Glu & 0.741 & 13.092 & -48.370 & 0.981 & 5.09 & 2.214 & -14.135 & 50.032 & 0.976 & 3.40 \\
\hline $\mathrm{Na}$ & 1.247 & 5.678 & -39.250 & 0.994 & 4.27 & 1.399 & -3.948 & 31.104 & 0.996 & 3.57 \\
\hline Gly & 0.856 & 13.410 & -60.550 & 0.987 & 4.94 & 2.192 & -14.205 & 52.031 & 0.981 & 3.39 \\
\hline $\begin{array}{l}\text { Sorb } \\
5^{\circ} \mathrm{C}\end{array}$ & 0.333 & 21.590 & -86.785 & 0.984 & 5.34 & 2.111 & -13.123 & 49.658 & 0.982 & 3.47 \\
\hline Glu & -0.153 & 18.297 & -65.019 & 0.980 & 3.10 & 2.329 & -7.372 & 29.930 & 0.984 & 6.52 \\
\hline $\mathrm{Na}$ & +0.019 & 17.736 & -84.415 & 0.989 & 2.58 & 2.250 & -7.540 & 37.240 & 0.989 & 6.48 \\
\hline Gly & +0.266 & 12.262 & -54.928 & 0.987 & 2.58 & 2.311 & -7.428 & 31.545 & 0.986 & 6.51 \\
\hline Sorb & -0.385 & 23.609 & -90.671 & 0.983 & 3.16 & 2.315 & -7.410 & 31.220 & 0.986 & 6.52 \\
\hline
\end{tabular}

Glu: glucose, $\mathrm{Na}: \mathrm{NaCl}$, Gly: glycerol and Sorb: sorbitol.

${ }^{a}$ Predicted optimum $a_{\mathrm{w}}$ for the radial growth rate.

${ }^{\mathrm{b}}$ Predicted colony growth rate $\left(\mathrm{mm}\right.$ day $\left.^{-1}\right)$ at the optimum $a_{\mathrm{w}}$.

${ }^{c}$ Predicted $a_{\mathrm{w}}$ for the shortest time required to form a visible colony.

${ }^{\mathrm{d}}$ Predicted time (days) required to form a visible colony at $a_{\mathrm{w}}(\mathrm{opt})_{2}$.

Another fungal growth parameter having high practical utility is the time required for a fungus to form a 2 -mm colony (Horner and Anagnostopoulous, 1973) or a 3-mm colony (Gibson et al., 1994). The latter parameter, called $t_{3}$, appears to be favoured in the predictive microbiology literature.

a)

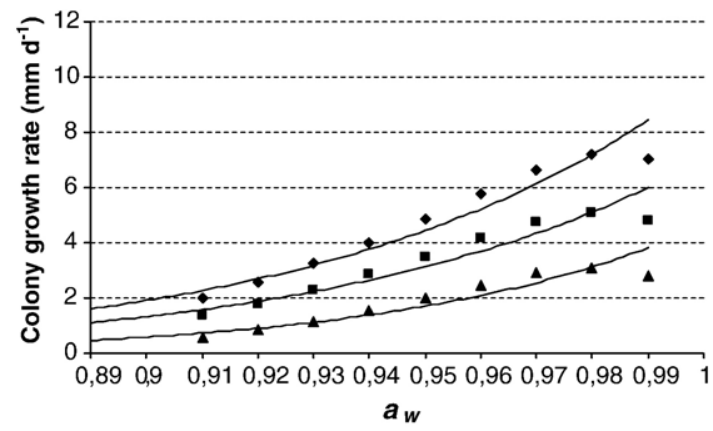

c)

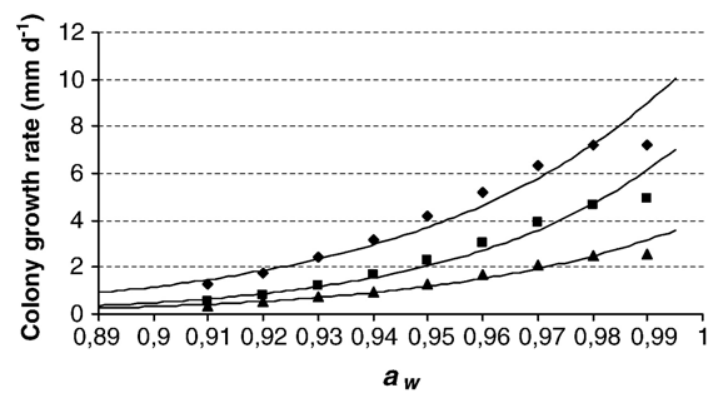

In this study, a third parameter, the time of visibility $\left(t_{\mathrm{v}}\right)$ described by Patriarca et al. (2001) as the time required to form a visible colony from the initial inoculum, was chosen. This parameter does not imply a colony size because when a colony becomes visible, its diameter usually exceeds $3 \mathrm{~mm}$. Product
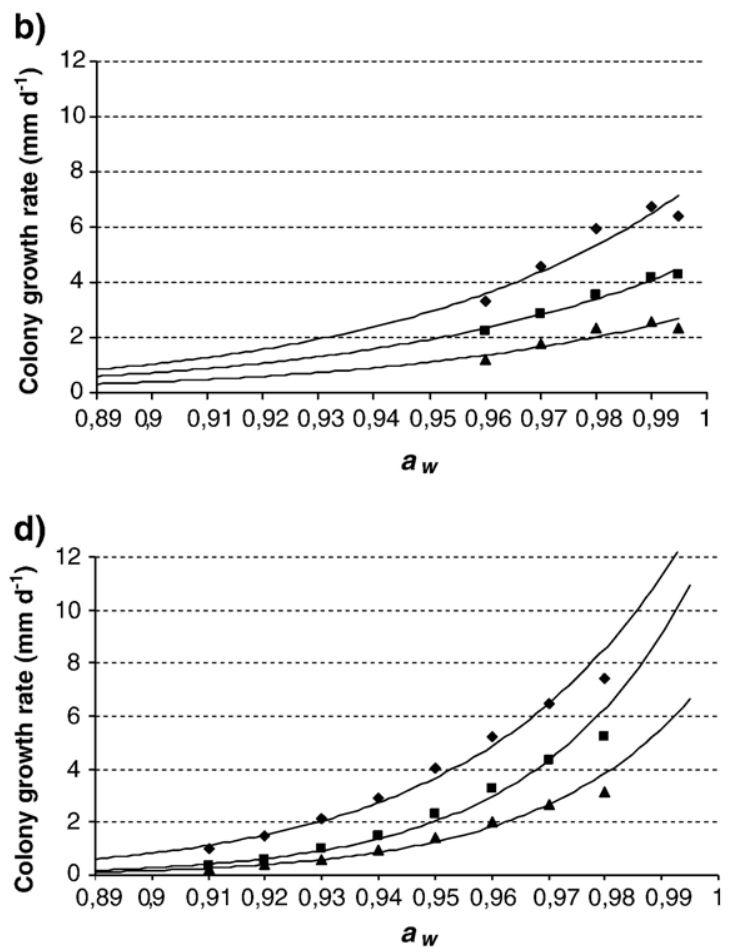

Fig. 2. Plots of colony growth rates, $g\left(\mathrm{~mm} \mathrm{~d}^{-1}\right)$, versus $a_{\mathrm{w}}$ for $B$. cinerea at $25(\bullet), 15(\boldsymbol{\square})$ and $5{ }^{\circ} \mathrm{C}(\boldsymbol{\Delta})$. Values of $a_{\mathrm{w}}$ were adjusted with glucose (a), NaCl (b), glycerol (c), and sorbitol (d). The continuous line indicates the fitted $g$ vs. $a_{\mathrm{w}}$ function, where $g=\exp \left(C_{0}+C_{1} b_{\mathrm{w}}+C_{2} b_{\mathrm{w}}^{2}\right)$ and $b_{\mathrm{w}}=\sqrt{\left(1-a_{\mathrm{w}}\right)}$. 
presenting such as colony is generally considered as spoiled and is rejected by the market. We applied our modelling approach to the $t_{\mathrm{v}}$ data, using the above-mentioned transformation (Eq. (5)). The $D i$ coefficients were calculated and the $a_{\mathrm{w}}(\mathrm{opt})_{2}$ and $t_{\mathrm{v}}$ (opt) values are shown for three incubation temperatures $\left(5^{\circ} \mathrm{C}, 15^{\circ} \mathrm{C}\right.$, $25^{\circ} \mathrm{C}$ ) in Table 2. Only slight differences were observed between the predicted $a_{\mathrm{w}}(\mathrm{opt})_{1}$ values of the radial growth model and the predicted $a_{\mathrm{w}}(\mathrm{opt})_{2}$ values of the $t_{\mathrm{v}}$ model. The time required to form a visible colony was found to increase with decreasing incubation temperature. Depending on the solute used, this time varied from 3 to 3.5 days at $25{ }^{\circ} \mathrm{C}$, approximately doubling at $5{ }^{\circ} \mathrm{C}$. These results are in accordance with our experimental observations: the fungus needed 4 days to form a visible colony at 25 or $15^{\circ} \mathrm{C}$ and 6 to 7 days at $5^{\circ} \mathrm{C}$ at water activities ranging from 0.98 to 0.995 . At the optimum $a_{\mathrm{w}}$ for growth, a conidial suspension placed on $\mathrm{NaCl}$-modified PDA required more time to form a visible colony than one placed on PDA modified with one of the other solutes. Thomas et al. (1988) found the minimum period required for production of a visible aerial mycelium on vineyards was 2 days at temperatures between 21 and $26^{\circ} \mathrm{C}$ and

a)

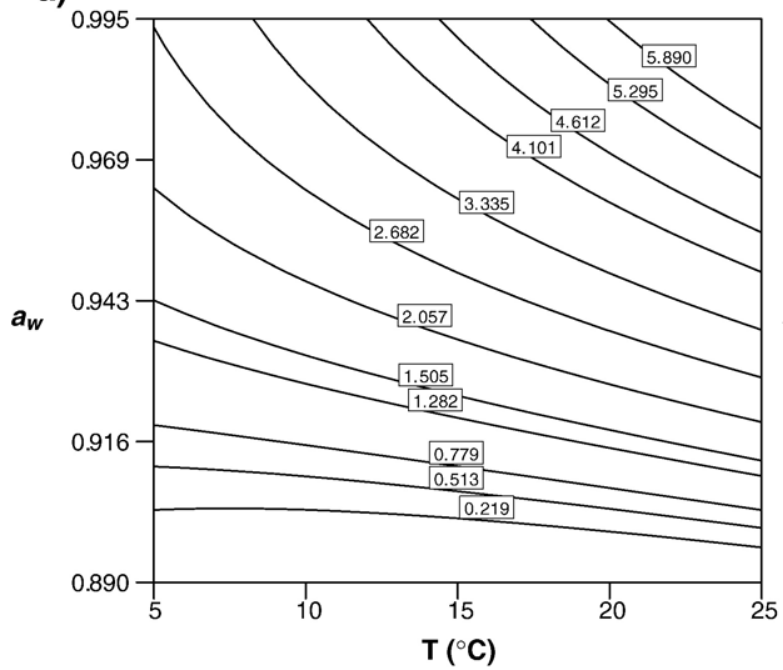

c)

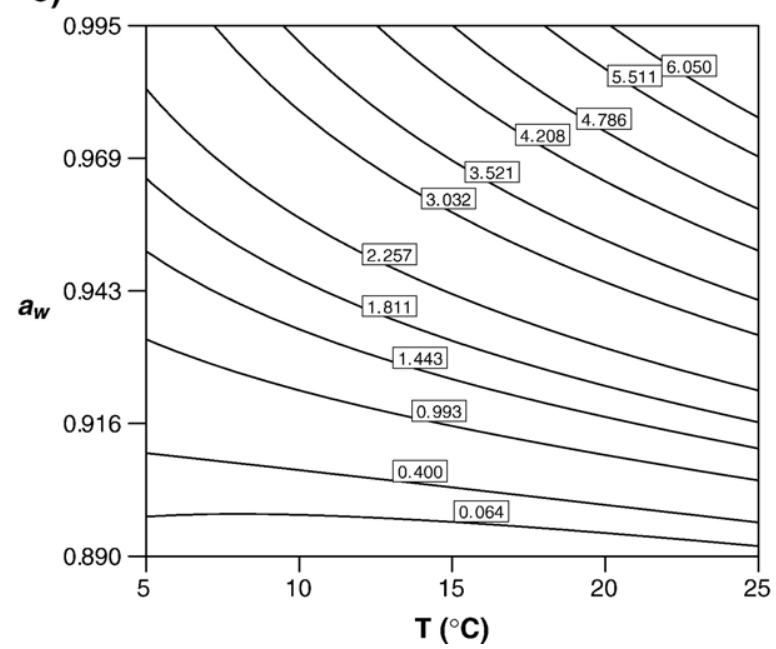

3 days at $16^{\circ} \mathrm{C}$. Production of aerial mycelium tended to fall as the relative humidity declined below $94 \%$ (Thomas et al., 1988), but can still occur at the relative humidity of $60 \%$ (Salinas et al., 1989).

\subsection{Combined effect of $a_{w}$ and temperature}

Contour plots of radial growth rate as a function of $a_{\mathrm{w}}$ and temperature were produced for each solute (Fig. 3). The plots show, within the range of the experimental data, a growth rate increasing with both $a_{\mathrm{w}}$ and temperature. The influence of $a_{\mathrm{w}}$ is much larger in comparison with the temperature. Whatever the solute model, growth at $25{ }^{\circ} \mathrm{C}$ is maximal at $a_{\mathrm{w}}$ values ranging from 0.96 to 0.995 (control). At low water activity and temperature, the glucose model is the one predicting the fastest growth $\left(0.219 \mathrm{~mm} \mathrm{~d}^{-1}\right)$ and the $\mathrm{NaCl}$ model predicts the slowest $\left(0.165 \mathrm{~mm} \mathrm{~d}^{-1}\right)$. All solute models make illogical predictions at $a_{\mathrm{w}}$ of 0.89 and at temperature of $5^{\circ} \mathrm{C}$; i.e. predicted values are slowly higher than observed values. Samapundo et al. (2005) have stressed that overfitting is typical of polynomial equation

b)

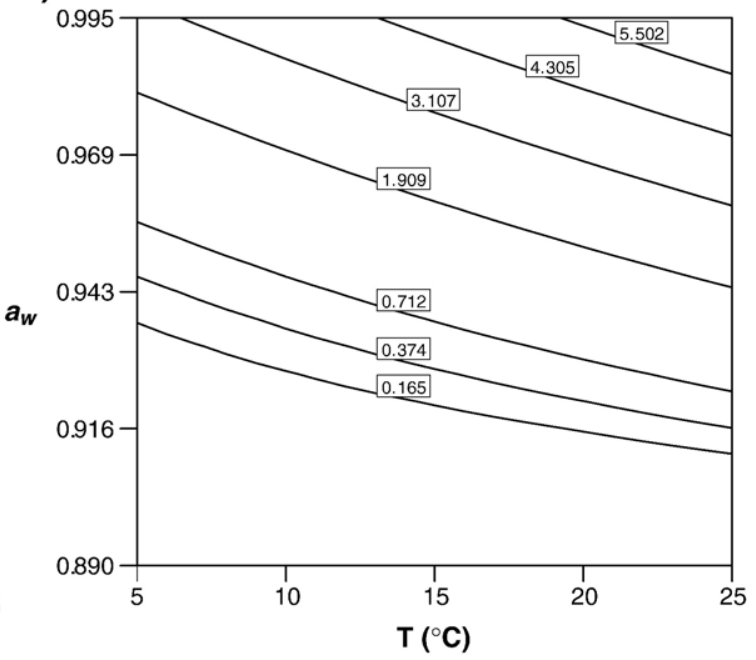

d)

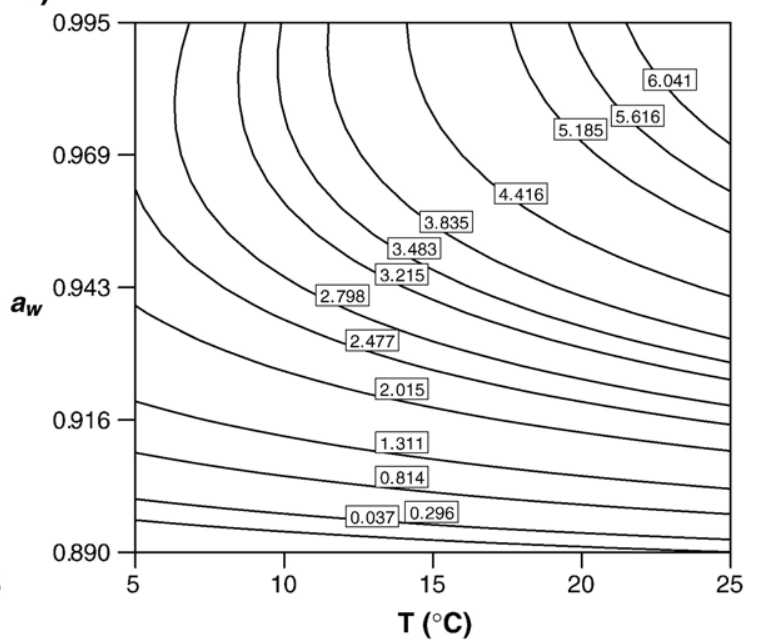

Fig. 3. Contour plots showing the combined effects of $a_{\mathrm{w}}$ and temperature on the radial growth rate $\left(\mathrm{g}=C_{0}+C_{1} b_{\mathrm{w}}+C_{2} b_{\mathrm{w}}^{2}+C_{3} T+C_{4} T^{2}+C_{5} b_{\mathrm{w}} \mathrm{T}\right)$ of $B$. cinerea in models based on glucose (a), $\mathrm{NaCl}$ (b), glycerol (c), and sorbitol (d). 
Table 3

Coefficients of growth rate secondary models, $\left(\mathrm{g}=C_{0}+C_{1} b_{\mathrm{w}}+C_{2} b_{\mathrm{w}}^{2}+C_{3} T+\right.$ $\left.C_{4} T^{2}+C_{5} b_{\mathrm{w}} T\right)$ for different solutes

\begin{tabular}{lcccc}
\hline Factor & Glu & $\mathrm{Na}$ & Gly & Sorb \\
\cline { 2 - 5 } & Coefficients & & & \\
\hline$C_{0}$ & $-1.439^{*}$ & $2.053^{*}$ & $-0.125^{\mathrm{ns}}$ & $-0.417^{\mathrm{ns}}$ \\
$b_{\mathrm{w}}$ & $40.774^{*}$ & $-6.484^{\mathrm{ns}}$ & $22.690^{*}$ & $30.548^{*}$ \\
$b_{\mathrm{w}}^{2}$ & $-116.289^{*}$ & $1.210^{\mathrm{ns}}$ & $-71.360^{*}$ & $-92.980^{*}$ \\
$T$ & $0.289^{*}$ & $0.248^{*}$ & $0.267^{*}$ & $0.242^{*}$ \\
$T^{2}$ & $-0.0000^{\mathrm{ns}}$ & $0.0015^{\mathrm{ns}}$ & $0.0015^{\mathrm{ns}}$ & $0.0018^{\mathrm{ns}}$ \\
$b_{\mathrm{w}} T$ & $-0.049^{*}$ & $-0.917^{*}$ & $-0.877^{*}$ & $-0.849^{*}$ \\
\hline
\end{tabular}

*Significant; ${ }^{\text {ns }}=$ not significant; Glu: glucose; Na: NaCl; Gly: glycerol; Sorb: sorbitol.

predictions under limit growth conditions. Table 3 provides the multiple regression coefficients relative to the quadratic polynomial model (Eq. (6)) applicable to $B$. cinerea. In the case of each solute, all coefficients have a significant effect, except coefficient $C_{0}$ in the glycerol and sorbitol models, linear and quadratic coefficient $\left(b_{\mathrm{w}}\right)$ in the $\mathrm{NaCl}$ model, and the quadratic effect of temperature $\left(T^{2}\right)$ in all models. A significant interaction between $b_{\mathrm{w}}$ and temperature is observed in all polynomial models. This coefficient has a negative effect, suggesting a synergistic interaction. The higher the absolute value of a linear coefficient $\left(b_{\mathrm{w}}\right.$ or $\left.T\right)$, the greater the influence of the corresponding factor ( $a_{\mathrm{w}}$ or temperature) on the growth rate of $B$. cinerea. Thus, in all cases, $a_{\mathrm{w}}$ is more influent than temperature. Applying the same approach with a third polynomial model, Samapundo et al. (2005) found a negative interaction between the effects of $b_{\mathrm{w}}$ and temperature on the growth rates of F. proliferatum and $F$. verticilloides on corn.

In summary, our results from quadratic polynomial model (Eq. (6)) and our statistical and graphical analyses confirm the previous findings that the $a_{\mathrm{w}}$ has a greater effect than temperature on radial fungal growth under in vitro conditions (Sautour et al., 2002; Samapundo et al., 2005; Lahlali et al., 2005, 2006). Haasum and Nielsen (1998) have likewise observed that the radial growth rate of $B$. cinerea is more affected by $a_{\mathrm{w}}$ than temperature, confirming our particular data on the same fungus.

\subsection{Secondary models validation}

In predictive microbiology, several mathematical and statistical indices are used to evaluate the ability of predictive models to describe experimental data adequately: regression coefficient, $F$-value, root mean square error (RMSE), and bias and accuracy factors (Ross, 1996; te Giffel and Zwietering, 1999; Dantigny et al., 2005b). The $r^{2}$ coefficient of a model measures the fraction of the variation explained by the model. The closer the $r^{2}$ value is to 1.00 , the better the data are predicted by the model. In our fungal study, the value of this coefficient was consistently very high for secondary model (Eq. (2)), exceeding 97\% whatever the solute and incubation temperature (Table 4). The RMSE was reported to be the most simple and most informative measure of goodness of fit of model. The smaller the RMSE value, the better the performance of the model (Dantigny et al., 2005b). All models displayed a small RMSE value, ranging between 0.03 and 0.09 . On the basis of the same modelling approach, Valík and Piecková (2001), reported similar results for three fungal heat-resistant strains. The lack of fit test of the model was also considered. If $f_{\text {value }}<F_{\text {table, }}$, the model is accurate enough to describe the experimental data. The lack of fit test revealed no significant difference between observed and predicted values for secondary models (Eq. (2)), after growth in glucose-, sorbitol- or glycerol-modified medium. This test was inapplicable to the $\mathrm{NaCl}$ model because the number of variables was equal to the number of experiments.

Ross (1996) and te Giffel and Zwietering (1999) reported that a model should be considered 'fail safe' when the bias factor is below 1, whereas a model yielding a bias factor larger than 1.1 should be considered as 'fail dangerous' because the difference between observed and predicted growth rates would exceed $10 \%$. However, a bias factor of 0.5 indicates a poor model that is overly conservative as it predicts growth rates that are on average, twice as large as the observed values. The accuracy factor gives an indication of the average difference between the predictions and the observations (Ross, 1996). Table 4 shows for our secondary model (Eq. (2)) a bias factors ranging from 0.999 to 1.00 and an accuracy factor ranging from 1.072 to 1.17 . At the growth temperature $\left(25^{\circ} \mathrm{C}\right)$, the average difference between observed and predicted $B$. cinerea colony growth rates was $6.9 \%$ for the glucose model, $4.6 \%$ for the $\mathrm{NaCl}$ model, $2.8 \%$ for the glycerol model, and $7.2 \%$ for the sorbitol model. The results for $a_{\mathrm{w}}$ and temperature effects are compatible with those determined for other fungi. Samapundo et al. (2005) modelled at four temperatures $(15,22,25$, and $30{ }^{\circ} \mathrm{C}$ ) the effect of $a_{\mathrm{w}}$ on the growth rates of $F$. verticilloides and $F$. proliferatum. The bias factor ranged from 0.84 to 1.08 and the accuracy factor from 1.075 to 1.218 . At $25^{\circ} \mathrm{C}$, Valík and

Table 4

Evaluation of the performance the $g=\exp \left(C_{0}+C_{1} b_{\mathrm{w}}+C_{2} b_{\mathrm{w}}^{2}\right)$ models for $B$. cinerea placed at different temperatures in medium adjusted to the desired $a_{\mathrm{w}}$ with different solutes

\begin{tabular}{|c|c|c|c|c|c|c|c|c|c|c|c|c|}
\hline & \multicolumn{4}{|l|}{$25^{\circ} \mathrm{C}$} & \multicolumn{4}{|l|}{$15^{\circ} \mathrm{C}$} & \multicolumn{4}{|l|}{$5^{\circ} \mathrm{C}$} \\
\hline & Glu & $\mathrm{Na}$ & Gly & Sorb & Glu & $\mathrm{Na}$ & Gly & Sorb & Glu & $\mathrm{Na}$ & Gly & Sorb \\
\hline$r^{2}$ & 0.97 & 0.99 & 0.99 & 0.98 & 0.96 & 0.99 & 0.99 & 0.96 & 0.97 & 0.98 & 0.99 & 0.97 \\
\hline RSME & 0.09 & 0.10 & 0.03 & 0.09 & 0.09 & 0.20 & 0.09 & 0.2 & 0.16 & 0.30 & 0.04 & 0.17 \\
\hline$f_{\text {value }}$ & 0.61 & - & 1.15 & 2.67 & 1.97 & - & 1.89 & 2.02 & 0.89 & - & 2.25 & 2.40 \\
\hline$F_{\text {table }}(95 \%)$ & 4.10 & 4.46 & 4.10 & 4.10 & 4.10 & 4.46 & 4.10 & 4.10 & 4.10 & 4.46 & 4.10 & 4.10 \\
\hline Bias factor & 0.999 & 1.005 & 1.000 & 0.999 & 1.000 & 1.004 & 0.999 & 1.000 & 1.000 & 1.000 & 0.999 & 1.000 \\
\hline Accuracy factor & 1.069 & 1.046 & 1.028 & 1.072 & 1.081 & 1.041 & 0.999 & 1.170 & 1.080 & 1.031 & 1.033 & 1.140 \\
\hline
\end{tabular}

Glu: glucose, $\mathrm{Na}: \mathrm{NaCl}$, Gly: glycerol and Sorb: sorbitol. _.: No 'lack of fit' detected. 
Table 5

Statistical and mathematical performance evaluation of secondary models (Eq. (6)) for $B$. cinerea growth in the presence of different solutes

\begin{tabular}{lcccc}
\hline & Glu & Na & Gly & Sorb \\
\hline$r^{2}$ & 98.6 & 93.9 & 95.4 & 94.2 \\
RSME & 0.26 & 0.54 & 0.50 & 0.57 \\
$f_{\text {value }}$ & 1.07 & 2.30 & 1.57 & 1.94 \\
$F_{\text {table }}(95 \%)$ & 2.04 & 2.04 & 2.04 & 2.04 \\
Bias factor & 0.957 & 1.036 & 0.950 & 0.860 \\
Accuracy factor & 1.089 & 1.070 & 1.120 & 1.260 \\
\hline
\end{tabular}

Glu: glucose; Na: NaCl; Gly: glycerol; Sorb: sorbitol.

Piecková (2001) reported a bias factor ranging from 1.007 to 1.014 and an accuracy factor from 1.070 to 1.106 .

In our quadratic polynomial models (Eq. (6)), the percentage variation explainable by the model is 95.4, 94.2, 98.6 and 93.9\% for the glycerol, sorbitol, glucose, and $\mathrm{NaCl}$ models respectively (Table 5). The smallest RSME value is observed with the glucose model $(0.26)$, followed by the glycerol, $\mathrm{NaCl}$, and sorbitol models with $0.50,0.54$, and 0.57 respectively. The lack of fit is significant only in the case of the $\mathrm{NaCl}$ model. The bias and accuracy factors for the glycerol, glucose, and $\mathrm{NaCl}$ are close to 1 , indicating that the models are good predictors of the true mean $B$. cinerea colony growth rate. In the case of the sorbitol model, a bias factor below 1 would suggest that the model is fail-safe for $B$. cinerea, yet this is not so, since the average difference between predicted and real growth rates is about $26 \%$. This difference is much lower in the case of the glucose, glycerol, and $\mathrm{NaCl}$ models ( $9 \%, 12 \%$, and $7 \%$ respectively) (Table 5). Using another polynomial model, Samapundo et al. (2005) reported, for both Fusarium isolates studied, a difference of $25.4 \%$ between predicted and observed colony growth rates in the case of glycerol used as humectant.

\section{Conclusion}

We described here a first model predicting $B$. cinerea growth rate according to environmental factors such as temperature and $a_{\mathrm{w}}$. Models developed here are based on 'in vitro' experiments carried out with glycerol, sorbitol, glucose and $\mathrm{NaCl}$-modified medium. The results show a significant effect of water activity and temperature on the radial growth rate of $B$. cinerea highlighting that the fungal growth decreases when water activity of the medium and temperature are low.

Secondary models (Eqs. (2) and (6)) described here can both predict, within the limits of our experiments, the $B$. cinerea growth rate and the time required for this fungus to form a visible colony. Yet we have noted growth rate overfitting in the polynomial models used (Eq. (6)) in case of low water activity and temperature. Secondary polynomial models should thus be used with caution when assessing the relationship between environmental factors and fungal growth. In contrast, our secondary models (Eq. (2)) offer good accuracy and predict even the slowest growth observed in our experiments. Beside secondary models used here to predict the growth of grey mould under 'in vitro' conditions, literature describes other models such as the linear Arrhenius-Davey equation (Davey, 1989) and the cardinal modelling approach (Dantigny, 1998; Sautour et al., 2001, 2002). These models could also be applied in the same way to predict the radial growth of $B$. cinerea.

Our $t_{\mathrm{v}}$ model (Eq. (5)) addresses an additional aspect of what is likely to happen in a $B$. cinerea-infected commodity characterized by a given water activity. Nevertheless it is important to bear in mind that such predictive growth rate and $t_{\mathrm{v}}$ models are designed to fit 'in vitro' data. Most likely, the predicted growth will be faster than growth under natural conditions, because the artificial medium is probably richer in nutrients (Lahlali et al., 2005). Furthermore, any extrapolation to natural conditions remains hazardous, because other factors such as interactions between microflora and the oxygen or carbon dioxide level may be involved. All results developed here could be applied in practice to various commodities susceptible to grey mould infection, as we have used multiple solutes to adjust the water activity. Implementation of these results should contribute to elaborating a more efficient control strategy against grey mould on commodities in field and storage conditions.

\section{Acknowledgements}

The authors thank the AUF (Agence Universitaire de la Francophonie), the Plant Pathology Unit of Gembloux University (Belgium), and the Department of Phytopathology of the National School of Agriculture of Meknès (Morocco) for their financial contributions to this paper.

\section{References}

Abadias, M., Teixidõ, N., Usall, J., Vinãs, I., Magan, N., 2000. Solute stress affect growth patterns, endogenous water potentials and accumulation of sugars and sugars alcohols in cells of the biocontrol yeast Candida sake. Journal of Applied Microbiology 89, 1-10.

Agrios, G.N., 1988. Plant Pathology, 3ed. Academic Press, Inc. New York. 803 pp. Beuchat, L.R, Pitt, J.I., 1990. Influence of solute, pH, and incubation temperature on recovery of heat-stressed Wallemia sebi conidia. Applied and Environmental Microbiology 56, 2545-2550.

Blakeman, J.P., 1980. Behavior of conidia on aerial plant surfaces. In: ColeySmith, J.R., Verhoeff, K., Jarvis, W.R. (Eds.), The Biology of Botrytis. Academic Press, London, pp. 115-151.

Bondoux, P., 1992. Maladies de conservation des fruits à pépins: pommes et poires. INRA, Paris, France. 173 pp.

Cahagnier, B., Melcion, B., Richard-Molard, D., 1995. Gowth of Fusarium moniliforme and its biosynthesis of fumonisin $\mathrm{B} 1$ on maize grain as a function of different water activities. Letters in Applied Microbiology 20, 247-251.

Cole, L., Dewey, F.M., Hawes, C.R., 1996. Infection mechanisms of Botrytis species: pre-penetration and pre-infection processes of dry and wet conidia. Mycological Research 100, 277-286.

Cuppers, H.G.A.M., Oomes, S., Brul, S., 1997. A model for the combined effects of temperature and salt concentration on growth rate of food spoilage moulds. Applied and Environmental Microbiology 63, 3764-3769.

Dantigny, P., 1998. Dimensionless analysis of the microbial growth rate dependance on sub-optimal temperatures. Journal of Industrial Microbiology and Biotechnology 21, 215-218.

Dantigny, P., Guilmart, A., Bensoussan, M., 2005a. Basis of predictive mycology. International Journal of Food Microbiology 100, 187-196.

Dantigny, P., Guilmart, A., Radoi, F., Bensoussan, M., Zwietering, M., 2005b. Modelling the effect of ethanol on growth rate of food spoilage moulds. International Journal of Food Microbiology 98, 261-269.

Davey, K.R., 1989. A predictive model for combined temperature and water activity on microbial growth during the growth phase. Journal of Applied Bacteriology 67, 483-488. 
Elad, Y., 1996. Mechanisms involved in the biological control of Botrytis cinerea incited diseases. European Journal of Plant Pathology 102, 719-732.

El-Halouat, A., Debevere, J.M., 1997. Effect of water activity, modified atmosphere packaging and storage temperature on spore germination of moulds isolated from prunes. International Journal of Food Microbiology 35, 41-48.

Ellison, P., Ash, G., McDonald, C., 1998a. An expert system for the management of Botrytis cinerea in Australian vineyards (I: Development). Agricultural Systems 56, 185-207.

Ellison, P., Ash, G., McDonald, C., 1998b. An expert system for the management of Botrytis cinerea in Australian vineyards (II: Validation). Agricultural Systems 56, 209-224.

Gibson, A.M., Hocking, A.D., 1997. Advances in the predictive modelling of fungal growth in food. Trends in Food Science and Technology 8, 353-358.

Gibson, A.M, Baranyi, J., Pitt, J.I., Eyles, M.J., Roberts, T.A., 1994. Predicting fungal growth: the effect of water activity on Aspergillus flavus and related species. International Journal of Food Microbiology 23, 419-431.

Gindro, K., Pezet, R., 2001. Effects of long-term storage at different temperatures on conidia of Botrytis cinerea Pers.: Fr. FEMS Microbiology Letters 204, 101-104.

Haasum, I., Nielsen, P.V., 1998. Ecophysiological characterization of common food-borne fungi in relation to $\mathrm{pH}$ and water activity under various atmospheric compositions. Journal of Applied Microbiology 84, 451-460.

Horner, K.J., Anagnostopoulous, G.D., 1973. Combined effects of water activity, $\mathrm{pH}$ and temperature on the growth and spoilage potential of fungi. Journal of Applied Bacteriology 36, 427-436.

Jarvis, W.R., 1977. Botryotinia and Botrytis Species; Taxonomy, Physiology and Pathogenicity. Monograph No. 15. Canada Department of Agriculture, Ottawa.

Jarvis, W.R., 1980. Taxonomy. In: Coley-Smith, J.R., Verhoeff, K., Jarvis, W.R. (Eds.), The Biology of Botrytis. Academic Press, London, pp. 1-18.

Jennings, D.H., 1983. Some aspects of physiology and biochemistry of marine fungi. Biological Review 58, 423-459.

Jijakli, M.H., Lepoivre, P., 1998. Characterization of an exo- $\beta$-1,3-glucanase produced by Pichia anomala strain K, antagonist of Botrytis cinerea on apples. Phytopathology 88, 335-343.

Köhl, J., Molhoek, W.M.L., Van Der Plas, C.H., Fokkema, N.J., 1995. Effect of Ulocladium atrum and other antagonist on sporulation of Botrytis cinerea on dead lily leaves exposed to field conditions. Phytopathology 85, 393-401.

Lahlali, R., Serrhini, M.N., Jijakli, M.H., 2005. Studying and modelling the combined effect of water activity and temperature on growth rate of P. expansum. International Journal of Food Microbiology 103, 315-322.

Lahlali, R., Serrhini, M.N., Friel, D., Jijakli, M.H., 2006. In vitro effects of water activity, temperature, and solutes on the growth rate of $P$. italicum Wehmer and $P$. digitatum Sacc. Journal of Applied Microbiology 101 (3), 628-638.

Marín, S., Sanchis, V., Vinas, I., Canela, R., Magan, N., 1995. Effect of water activity and temperature on growth and fumonisin B1 and B2 production by Fusarium proliferatum and $F$. moniliforme on maize grain. Letters in Applied Microbiology 21, 298-301.

Marín, S., Sanchis, V., Teixidó, A., Saenz, R., Ramos, A.J., Vinas, I., Magan, N., 1996. Water and temperature relations and microconidial germination of Fusarium moniliforme and F. proliferatum from maize. Canadian Journal of Food Microbiology 42, 1045-1050.

Marín, S., Magan, N., Belli, A., Ramos, A.J., Canela, R., Sanchis, V., 1999a. Two-dimensional profiles of fumonisin B1 production by Fusarium moniliforme and $F$. proliferatum in relation to environmental factors and potential for modelling toxin formation in maize grain. International Journal of Food Microbiology 51, 159-167.
Marín, S., Magan, N., Serra, J., Ramos, A.J., Canela, R., Sanchis, V., 1999b. Fumonisin B1 production and growth of Fusarium moniliforme and Fusarium proliferatum on maize, wheat, and barley grain. Journal of Food Science 64, 921-924

McMeekin, T.A., Olley, J.N., Ross, T., Ratkowsky, D.A., 1993. Predictive Microbiology: Theory and Application. Research Studies Press, Taunton, UK.

McMeekin, T.A., Olley, J.N., Ratkowsky, D.A., Ross, T., 2002. Predictive microbiology: towards the interface and beyond. International Journal of Food Microbiology 73, 395-407.

Patriarca, A., Vaamonde, G., Pinto, V.F., Comerio, R., 2001. Influence of water activity and temperature on the growth of Wallemia sebi: application of a predictive model. International Journal of Food Microbiology 68, 61-67.

Pitt, R.E., 1993. A descriptive model of mold growth and aflatoxin formation as affected by environmental conditions. Journal of Food Protection 56, 139-146.

Ross, T., 1996. Indices for performance evaluation of predictive models in food microbiology. Journal of Applied Bacteriology 81, 501-508.

Rousseau, S., Deneche, B., 2001. Effects of water activity $a_{\mathrm{w}}$ on the growth of some epiphytic microorganisms isolated from grape berry. Vitis 40 (2), $75-78$.

Salinas, J., Verhoeff, K., 1995. Microscopical studies of the infection of gerbera flowers by Botrytis cinerea. European Journal Plant Pathology 101, 377-386.

Salinas, J., Glandorf, D.C.M, Picavet, F.D., Verhoeff, K., 1989. Effects of temperature, relative humidity and age of conidia on the incidence of spotting gerbera flowers caused by Botrytis cinerea. Netherlands Journal of Plant Pathology 95, 51-94.

Samapundo, S., Devlieghere, F., De Meulenar, B., Geeraerd, A.H., Van Impe, J.F., Debevere, J.M., 2005. Predictive modelling of the individual and combined effect of water activity and temperature on the radial growth of Fusarium verticilloides and F. proliferatum on corn. International Journal of Food Microbiology 105, 35-52.

Sautour, M., Dantigny, P., Divies, C., Bensoussan, M., 2001. A temperature-type model for describing the relationship between fungal growth and water activity. International Journal of Food Microbiology 67, 63-69.

Sautour, M., Soares Mansur, C., Divies, C., Bensoussan, M., Dantigny, P., 2002. Comparison of the effects of temperature and water activity on growth rate of food spoilage moulds. Journal of Industrial Microbiology and Biotechnology 28, 311-316.

Skirdal, I.M., Eklund, T., 1993. Microculture model studies on the effect of sorbic acid on Penicillium chrysogenum, Cladosporium caldosporides and Ulocladium atrum at different $\mathrm{pH}$ levels. Journal of Applied Bacteriology 74, 191-195.

te Giffel, M.C., Zwietering, M.H., 1999. Validation of predictive models describing the growth of Listeria monocytogenes. International Journal of Food Microbiology 46, 135-149.

Teixidõ, N., Vinãs, I., Usall, J., Sanchis, V., Magan, N., 1998. Ecophysiological responses of the biocontrol yeast of Candida sake to water, temperature and pH stress. Journal of Applied Microbiology 84, 192-200.

Thomas, C.S., Marois, J.J., English, J.T., 1988. The effects of wind speed, temperature, and relative humidity on development of aerial mycelium and conidia of Botrytis cinerea on grape. Phytopathology 78, 260-265.

Valík, L., Piecková, E., 2001. Growth modelling of heat-resistant fungi: the effect of water activity. International Journal of Food Microbiology 63, $11-17$.

Williamson, B., Duncan, G.H., Harrison, J.G., Harding, L.A., Elad, Y., Zimand, G., 1995. Effect of humidity on infection of rose petals by dry-inoculated conidia of Botrytis cinerea. Mycological Research 99, 1303-1310. 